\title{
The Olusuba noun class system
}

\author{
Lilian Akoth Ochieng ${ }^{1}$, Furaha Chai $^{2}$ \\ ${ }^{1}$ Department of Linguistics and Foreign Languages, School of Arts and Social Sciences: Moi University, Eldoret, Kenya \\ ${ }^{2}$ Department of Literature, Languages and Linguistics, Faculty of Arts and Social Sciences: Egerton University, Kenya
}

\section{Email address:}

lilian.akoth28@yahoo.com (L. A. Ochieng),optiondz@yahoo.co.uk (F. Chai)

\section{To cite this article:}

Lilian Akoth Ochieng, Furaha Chai. The Olusuba Noun Class System. International Journal of Language and Linguistics. Vol. 2, No. 5, 2014, pp. 295-300. doi: 10.11648/j.ijl1.20140205.11

\begin{abstract}
Noun classification is one of the prime markings of any Bantu language. It is characterized by the categorization of nouns into noun classes which often pair into singular and plural pairings. These classes are often marked with a numbering system. Suba language being a Bantu language has a noun class system typical of the other Bantu languages and because the language has hardly any evidence of a description of any aspect of its grammar this study seeks to describe this significant aspect of it, laying emphasis on the role of syntax in the morphological structure of the noun. The study took a qualitative approach with the descriptive research design. It was guided by the theory of distributed morphology introduced in 1993 by Morris Halle and Alec Marantz. The theory demonstrates the inter-relatedness between the various components of grammar (phonology, morphology, syntax and semantics). Data was collected in Mfangano Island, which is a homogeneous set up of Suba indigenous people. A sample of forty elders was purposively selected to provide the data. Focus group discussion and elicitation methods were used to collect a corpus of the Suba language which was recorded through audio taping and field notes. The recorded data was then analyzed using the item-and-arrangement approach of morphological structure analysis. This revealed that the classification of the Olusuba noun into a class is motivated by both the morpholosyntactic realization of the noun and the semantics of the noun.
\end{abstract}

Keywords: Olusuba, Morphosyntax, Noun Classes, Proto-Bantu

\section{Introduction}

Bantu languages typically have an extensive nounclassification system, with obligatory prefixing to mark gender and number, and concord between the noun phrase and verb or any other category within the structure. Noun classes indicate more than just membership, they usually also convey information about grammar number, meaning that singular and plural forms of a noun are classified in different classes

Individual noun classes are commonly referred to with a numbering system originally devised by whelm Bleak during the $19^{\text {th }}$ century. It was later expanded by Carl Meinhof, thus the name 'Bleek-Meinhof system' The Bantu noun class system has been extensively studied, this is because alongside verbal extensions, it is the next most significant feature of Bantu languages; that is, it is a typological feature used to classify languages.

This study, describes the classification and morphosyntactic structure of the Olusuba nouns. Following that Olusuba is one of the marginalized Bantu languages of
Kenya with hardly any description to its name and a threat of being consumed by Dholuo, a Nilotic language. I thought it wise that in the description of this language it were better if I focused on the very basic first: The noun class system. The study therefore looks at the possible classification of Olusuba noun and how the classification maps into the proto-Bantu noun classes and how the noun class system morphosyntactically interacts with the other elements in a linguistic structure.

Describing a language provides a structure for working through the grammatical description of that language at a reasonable level of inclusiveness, thus allowing for more comprehensive treatment of language-particular data in relation to pointing to relevant parts of the extensive literature on language universals. Austine (2003) ${ }^{[1]}$ says that the act of describing any aspect of a language comprises two activities, i.e. the collection, transcription and translation of primary data and a low-level analysis of these data. It is worth noting that, language description is in no way restricted to little-known languages, nor are such languages its central concern. Its central concern as 
Himmelmann (1998) ${ }^{[2]}$ says is the synchronic, nonprescriptive statement of the system of the language in question. The fact that descriptive linguistics is currently associated with works on little-known languages (as is the case in this study) is primarily due to the fact that descriptive techniques have been found to be highly useful and effective in 'opening up' little-known languages.

As I mentioned earlier, this study is focused on Suba language, a language with rich noun and verb morphology where both root and noun-and-verb-creating morphology are morphologically and syntactically transparent. It is an SVO language. All constituents in the nominal phrase agree with the lexical head. Verbal prefixes also concord (agree) with the lexical head of the subject, a feature which is characteristic of all Bantu languages.

Suba language is the language of the Suba people (Abasuba) found in Kenya and Tanzania. Ayot, (1987) ${ }^{[10]}$, Rotland and Okombo, (1986) ${ }^{[13]}$, identify six Olusuba dialects spoken in Kenya:- Olwivwang'o:- spoken in Mfangano, Rusinga, Takawiri and Kibwogi Islands. Ekikuna:- spoken in Kaksingri, Ekingoe:- spoken in Ngeri, Ekigase:- spoken in Gwasi hills, Ekisusuuna:- spoken in Migori and finally Olumuulu :-spoken in Muhuru bay. Of the six dialects four have become almost extinct, leaving only the Olwivwango spoken in the Islands and Ekigase spoken in Gwasi. The two are however very closely related morphologically. The study focused on Olwivwango dialect because of the two, it is the dominant since it has more speakers.

The population of the Suba native speakers in Kenya totals to around 139,271 (Census report, 2010) ${ }^{[14]}$ most of whom have lost the ability to speak and understand their native language. Ogone, (2008) ${ }^{[12]}$ says that, in some communities the Suba language and culture can be considered as endangered, in others perhaps it is more fitting to classify them as severely endangered or even extinct. This could be attributed to their settlement patterns. The fact that the Suba people live in different geographical locations, has meant that some communities have been more exposed to outside linguistic and cultural influences than others thus leading to a considerable variation concerning the degree of competence of speakers. Some Suba people, who are fluent in Dholuo, and have Luo spouses and names, cannot speak their extinct mother tongue, practice their culture, or pass their own history to the next generation (UNESCO, 2007) ${ }^{[3]}$

English (the official language), Kiswahili (the national language and now also official language) and Dholuo, have gradually gained dominance, thus, undermining the Suba language and culture. Many Suba people have made a deliberate choice of not passing on their language to their children at the earliest possible time, opting for those languages that offer socio-economic and political gains at the local, national and international levels.

Grimes (2000) ${ }^{[4]}$ calls for a linguistic description of the minority and threatened languages as a measure towards preservation of the same. Hale (1992) ${ }^{[5]}$ effectively argues that, the loss of diversity that language extinction represents is a scientific human tragedy. Ngugi Wa Thiongo (2009) ${ }^{[6]}$ echoes the same when he posits that language is the carrier of culture and to starve or kill a language is to starve and kill a people's culture. He argues that a renaissance of the threatened languages is a necessary step in the restoration of the respective speech community's wholeness.

\section{Morphological Structure of the Nouns}

Morphological structure amounts to recognizing relations among whole words in the mental lexicon based on similarities in meaning and form. It entails looking at the lexicon then breaking it down to discover its primitives and how they are brought together.

This study used the item-and-arrangement approach of morphological structure analysis. This approach takes a structuralistic approach to word analysis, unlike the itemand-process approach which concerns itself with the operation of process of simpler words resulting in complex ones. The item-and-arrangement approach proceeds from a picture of each language as a set of elements and the patterns in which those elements occur. This way of analyzing word forms treats words as if they were made of morphemes put after each other like beads in a string.

To arrive at the morphemes and their possible set of rules of combinations a linguistic paradigm of declensions of nouns was developed from the data. This resulted in an exhaustive collection of forms of each of the words.

The word forms of the various nouns were conveniently arranged into tables by classifying them according to shared inflectional categories nouns with same singular and plural prefixes were grouped together.

It should be noted that the inflectional categories used to group the word forms into paradigms were not arbitrarily chosen; they were based on Meinhof's Bantu noun Classification System of noun class belonging and grammatical number Meinhof,(1906) ${ }^{[9]}$. Meinhof considers the two as the most important features relevant to Bantu noun classes. He, however reports that in a number of languages, a third important feature; animacy does exist. That is whether, or not the thing referred to by the noun is a human being or an animal or non-living. This third feature appeared very significant in classification of Olusuba nouns because it was noted that animal names in Olusuba have close to similar prefixing thus could all belong to the same group. Names of human beings too had similar prefixing. Similarly inanimate things too had very close prefixes. Having drawn paradigms of the nouns, and their various declensions, a scrutiny was done and nouns with similar attributes were grouped together. This was based on the similarities of nominal and pronominal prefixes used by the nouns.

Following Meinhof's idea of classification, the Olusuba 
nouns sharing similar singular prefix and plural prefix were grouped together in classes as follows

(1)

Class 1 contains nouns with noun class prefix' (o) 'mu' and '(a) 'wa'for plural. It mostly consists of people, although some inanimate nouns can also be classified here because they have the same pronominal prefix

Class 2 contains an assortment, most tree names fall in this class. They use the prefix' (o) mu' for singular and '(e) mi' for plural.

Class 3 contains many different concepts but most animal names fall in this category It uses the prefix '(e) n' for both singular and plural.

Class 4 contains inanimate objects and is the class used for the impersonal 'it', it uses the prefix '(e) ki' for singular and '(e) bi' for plural.

Class 5 contains mainly but not exclusively large things and liquids and can also be used to create augmentatives. It takes the prefix (i) ri' for singular and '(a) ma' for plural.

Class 6 contains mainly small things and can be used to create diminutives, countries and abstract nouns. They take the prefix (a) ka' for singular and '(a) bu' for plural.

Class 7 contains the names of many different things including the names of languages e. g. Olusuba, Oluzungu, oluwvango, they take the singular prefix '(o) lu' and the plural (e) $n$

Class 8 is a rarely used class but is occasionally used to create pejorative forms e. g. gubwa very big dog. It uses the prefix (o) gu for singular and (a) ga for plural.

Class 9 mainly used for action e.g. kukola 'to do'. It takes the prefixes (o) ku for singular and (a) ma for plural.

Class 10 has no singular - plural distinction. It is used for mass nouns. It takes the prefix (o) tu for both singular and plural forms, e. g. tubaka 'a nap- little sleep'

From the data presented a generalization can be made, that, Olusuba noun forms( just like other Bantu languages) are morphologically realized using the prefixes on the nouns and their agreement markers on other syntactic constituents like the adjectives, numerals, verbs among others. It has a systematic morphology that identifies its nouns and classifies them into a definite number of noun classes. The noun class system treats singular and plural nouns as distinct, each with different affixes unique to its own class. The specific initial vowel used will depend on the class of the noun with which it is associated. It denotes the singular or plural form of the noun depending on the class.

There are only a few cases where prefixes overlap: the singulars of Classes I and 2 (both beginning with $m u$-); the singular of Class 3 and plurals of Classes 3 and 7 (all beginning with $n$-); and the plurals of Classes 5 and 9 (both $m a-)$. Genuine ambiguity, however, is rare, since even where the noun prefixes are the same; the other prefixes are often different. For example there can be no confusion between omuntu (Class I) 'person' and omuntu (Class 2) 'seat' in the sentences Omuntu ali wano 'The person is here' and Omuntu guli wano 'The seat is here' because the verb prefixes $a$ - (Class 1) and gu- (Class 2) are different, even if the noun prefixes are the same. The same is true with the singular and plural of Class 3: Embwa erya 'The dog is eating' vs Embwa zirya 'The dogs are eating' (compare English The sheep is eating vs The sheep are eating where the noun is invariant but the verb distinguishes singular from plural)

\section{Noun Classes}

The Proto- Bantu noun classification system counts singular and plural forms as two separate noun classes, and it accommodates up to 22 noun classes. For this study the singular-plural pairs will be treated as one class. By the former method (singular/plural separate) there are 17 classes while by the latter (singular/plural same class) there are 10 , since there are two pairs of classes with identical plurals and one class with no singular-plural distinction. The following illustration shows how the Olusuba noun class system maps into the proto-Bantu noun class system

Table1. Proto-Bantu Noun Class System

\begin{tabular}{lll}
\hline Olusuba Class & Number & Proto-Bantu Class \\
\hline I & Singular & 1, \\
II & Plural & 2 \\
& Singular & 3 \\
III & Plural & 4 \\
& Singular & 9 \\
IV & Plural & 10 \\
& Singular & 7 \\
V & Plural & 8 \\
& Singular & 5 \\
VI & Plural & 6 \\
& Singular & 12 \\
VII & Plural & 14 \\
& Singular & 11 \\
VIII & Plural & 10 \\
& Singular & 20 \\
IX & Plural & 22 \\
X & Singular & 15 \\
\hline
\end{tabular}

Following the above mapping, a possible classification system for the Olusuba nouns was therefore arrived at as follows:

Table 2. Olusuba noun classes

\begin{tabular}{|c|c|c|c|c|c|}
\hline & class & $\begin{array}{l}\text { Example } \\
\text { singular }\end{array}$ & Gloss & plural & gloss \\
\hline 1 & Mu-wa & o-mwana & child & a-wana & children \\
\hline 2 & $\mathrm{Mu}-\mathrm{mi}$ & o-muti & Tree & e-miti & Trees \\
\hline 3 & $n-n$ & e-ngoko & hen & e-ngoko & hens \\
\hline 4 & Ki-bi & e-kitabu & A book & e-bitabu & books \\
\hline 5 & li-ma & i-toke & banana & amatoke & bananas \\
\hline 6 & Ka-bu & Ka-nafu & laziness & Ba-nafu & Laziness \\
\hline 7 & Lu-n & O-lusuba & olusuba & ----- & ------- \\
\hline 8 & Gu-ga & Gu-bwa & Bad dog & Gu-bwa & Bad dog \\
\hline 9 & $\mathrm{Ku}-\mathrm{ma}$ & $\begin{array}{l}\mathrm{Ku}- \\
\text { tumbula }\end{array}$ & To boast & $\begin{array}{l}\text { ma- } \\
\text { tumbula }\end{array}$ & To boast \\
\hline 10 & $\mathrm{Tu}$ & Tu-baka & A little sleep & --- & ----- \\
\hline
\end{tabular}


As can be deduced from table 4 above, the morphology of Olusuba nouns is striking in its lack of free root morphemes; this in adherence to the theory of distributed Morphology which stipulates that the abstract morphemes that comprise words are held to be completely empty of phonological information until after the syntactic component has finished manipulating them. That is, the structure of a word is worked out before there are any actual words present, a word will only be realized after consulting the word class hence the features to pick. Whereas the English words like, girl, chair are acceptably

(2)

\begin{tabular}{|c|c|c|}
\hline Noun class 1: & $\begin{array}{l}\text { omugaka, } \\
\text { 'man', }\end{array}$ & $\begin{array}{l}\text { omwana, } \\
\text { 'baby' }\end{array}$ \\
\hline Plural: & $\begin{array}{l}\text { awagaka, } \\
\text { 'men' }\end{array}$ & $\begin{array}{l}\text { awana, } \\
\text { 'babies' }\end{array}$ \\
\hline Noun class 2: & $\begin{array}{l}\text { omuti, } \\
\text { 'tree', }\end{array}$ & $\begin{array}{l}\text { omufuko, } \\
\text { 'bag' }\end{array}$ \\
\hline Plural & $\begin{array}{c}\text { emiti } \\
\text { Trees }\end{array}$ & $\begin{array}{l}\text { emifuko } \\
\text { bags }\end{array}$ \\
\hline Noun class 3: & $\begin{array}{l}\text { enzovu, } \\
\text { 'elephant' } \\
\text { Plural: enzovu, } \\
\text { 'Elephants' }\end{array}$ & $\begin{array}{l}\text { enyamu, } \\
\text { 'cat' } \\
\text { enyamu, } \\
\text { 'frogs' }\end{array}$ \\
\hline
\end{tabular}

The root of a given noun can also be combined with an appropriate prefix to convey descriptive information about the noun. Consider the example-wala 'girl' the meaning of the root noun can fluctuate depending on the prefix used and this may even change the class of the noun;

(3)

$$
\begin{aligned}
& \text { m-wala------girl (class 1) } \\
& \text { ka-wala------girl; diminutive (class 6) } \\
& \text { gu-wala--------girl; ugly big girl (class 8) }
\end{aligned}
$$

Some Olusuba nouns decline to show size, for example the diminutive and augmentatives

Table 3. Noun Declensions to show diminutives and augmentatives

\begin{tabular}{llll}
\hline Word & gloss & Diminutive & Augmentative \\
\hline omwala & girl & Ki-mwala & Gu-wala \\
omugaka & Old man & Ki-mugaka & Gu-gaka \\
okukono & hand & Ki-kukono & Gu-kono \\
\hline
\end{tabular}

\section{Morphosyntactic Realization}

\subsection{Number}

Number in Olusuba nouns is indicated by replacing the singular prefix with the plural prefix. The specific prefix used is determined by the class of the noun with which it is associated and whether it is singular or plural. This is denoted by an initial vowel which mostly is bi-morphemic For example omusajja 'man', abasajja 'men'; ekisanirizo 'comb', ebisanirizo 'combs'. All word classes agree with nouns in number and class. used without inflections, their Olusuba equivalents o- $m$ wala and, e-n-tewe are meaningless if used without the appropriate inflections. The 'o-' 'm-' and 'e-' ' $n$-' are bound prefixes denoting the noun class and number of the noun.

It must be noted that this is so because as Ngonyani (1996) ${ }^{[7]}$ says, the Bantu noun form must convey not only the basic idea but it must also contain morphemes conveying the noun class and the number of the noun in question.

Examples of nouns belonging to some of the classes are;

$$
\begin{aligned}
& \text { omukazi, } \\
& \text { 'wife' } \\
& \text { awakazi, } \\
& \text { 'wives' } \\
& \text { omutoka } \\
& \text { 'vehicle } \\
& \text { emitoka } \\
& \text { vehicles } \\
& \text { embua, } \\
& \text { 'dog' } \\
& \text { embua, } \\
& \text { 'dogs' }
\end{aligned}
$$

$\begin{array}{ll}\text { omwizukulu, } & \begin{array}{l}\text { omuaruku } \\ \text { 'co-wife' } \\ \text { awizukulu, }\end{array} \\ \text { 'grandchildren' } & \text { awiaruku } \\ \text { 'co-wives' }\end{array}$

$$
\begin{aligned}
& \text { engoko } \\
& \text { chicken } \\
& \text { engoko } \\
& \text { 'chicken' }
\end{aligned}
$$

\subsection{Adjectives}

As is the case in nearly all Bantu languages, adjectives and number roots must agree in noun class and number with the nouns they qualify. For example:

$$
\begin{aligned}
& \text { Number roots: i) Awala wa-wiri } \\
& \text { 'Two girls' } \\
& \text { ii) Emiti i-wiri } \\
& \text { ' two trees' } \\
& \text { iii) Embuzi } \text {-wiri } \\
& \text { 'two goats' } \\
& \text { iv) amatoke a-wiri } \\
& \text { ' two bananas' } \\
& \text { i) omwala omulungi } \\
& \text { 'a beautiful girl' } \\
& \text { ii) awaala awamulungi } \\
& \text { ' Beautiful girls' } \\
& \text { iii) omuti omulungi } \\
& \text { 'Beautiful tree' } \\
& \text { iv) emiti emirungi } \\
& \text { 'beautiful trees' }
\end{aligned}
$$$$
\text { (5) Adjectives: }
$$

In these examples (5) the adjective '-lungi' beautiful changes its prefix according to the noun class and number (singular or plural) of the noun it is qualifying. In some cases the prefix causes the initial of the stem to change to ' $n$ - 'or ' $r$ '

\subsection{Pronouns}

The Olusuba pronouns can be declined for number (singular and plural), person (first second and third) and case (nominative, oblique and possessive). The pronouns decline to reflect their relationship to a verb or preposition. Case being a feature of government in syntax plays a vital role in the morphosyntax of Olusuba.The table below illustrates this. 
Table 4. Olusuba personal pronouns (nominative and oblique)

\begin{tabular}{lllllllll}
\hline Pronoun & Subjective singular & gloss & Subjective plural & gloss & Objective Singular & gloss & Objective plural & Gloss \\
\hline $1^{\text {st }}$ person & inze & I & Ifue & we & Ifue & me & ifwe & Us \\
$2^{\text {nd }}$ person & iwue & you & mbaaria & You & Iwue & You & muri & you \\
$3^{\text {rd }}$ person & iyie & he & Awu & they & Ekiae & Him & iwo & Them \\
$3^{\text {rd }}$ person & iyie & she & Awu & they & Ekiae & her & iwo & Them \\
$3^{\text {rd }}$ person & kiri & it & ekiae & they & ekiae & it & Ekiawu & them \\
\hline
\end{tabular}

\subsection{Possessive}

The possessive in Olusuba is indicated with a different particle for each singular and plural (according to the possessed noun). An alternative way of thinking about the Olusuba possessive is as a single word whose initial consonant cluster is altered to agree with the possessed noun in class and number.

Depending on the possessed noun, the possessive takes one of the following forms

(6)

- $\quad$ Singular wa, plural ba (Class I)

- $\quad$ Singular gwa, plural gya (Class II)

- $\quad$ Singular ya, plural za (Class III)

- $\quad$ Singular kia, plural bia (Class IV)

- $\quad$ Singular lia, plural ga (Class V)

- $\quad$ Singular ka, plural bwa (Class VI)

- $\quad$ Singular lwa, plural za (Class VII)

- $\quad$ Singular gwa, plural ga (Class VIII)

- $\quad$ Singular kwa, plural ga (Class IX)

- Twa (Class X)

This can be further exemplified in the following examples

(7)

(i) Ono nio omusaaza wange

This is my husband (class 1 singular)

(ii) wano nio awala baange

These are my girls (class 1 plural)

(iii) Omufuko guno no ogwange

This bag is mine (class 11 singular)

(iv) Ekiduuma kino ne ekiange

This cob of maize is mine (class IV singular)

(v) Kino ne epikapu kiange

This is my basket (class IV singular)

The first person possessive 'my' declines to suit the number and noun class of the possessed. The initial consonant cluster is altered to agree with the possessed noun in class and number.

If the possessor is a personal pronoun like 'hers', 'his', 'its' the separate possessive form is not used instead the following personal possessives apply:

(8)

- Wange 'my', wo 'your (singular possessor)', we 'his, her'; waffe 'our', wammwe 'your (plural possessor)', waabwe 'their' (Class I, singular possessed noun)

- Bange 'my', bo 'your (singular possessor)', be 'his, her'; baffe 'our', bammwe 'your (plural possessor)', baabwe 'their' (Class I, plural possessed noun)
- Gwange 'my', gwo 'your (singular possessor)', gwe 'his, her'; gwaffe 'our', gwammwe 'your (plural possessor)', gwabwe 'their' (Class II, singular possessed noun)

- Gyange 'my', gyo 'your (singular possessor)', gye 'his, her'; gyaffe 'our', gyammwe 'your (plural possessor)' gyabwe 'their' (Class II, plural possessed noun)

- Yange 'my', yo 'your', etc. (Class III, singular possessed noun)

The demonstrative pronouns too, decline to show variation depending on the noun class of the noun. The table below exemplifies the same.

Table 5. Declensions of demonstrative pronouns

\begin{tabular}{ll}
\hline Omwana ono & This baby \\
Awana wano & These babies \\
Omuti gono & This tree \\
Emiti gino & These trees \\
Emeza eno & This table \\
Emeza zino & These tables \\
Igi rino & This egg \\
Amagi gano & These eggs \\
Itoke rino & This banana \\
Amatoke gano & These bananas \\
\hline
\end{tabular}

Unlike a language like English, where the demonstrative retains its form whichever noun it is referring to, the demonstrative pronouns in Olusuba decline to suit the noun class and number of the noun in reference. In the table above ono, 'this' is for class1 singular, wano, 'this' class I plural, eno, 'this' class III singular zino, 'this' class III plural.

\section{Conclusion}

From the data collected and analyzed, it is clear that like other Bantu languages, Olusuba has a noun class system that involves singular and plural patterns as well as agreement markings triggered by these noun classes. The noun classes are identifiable by the prefixes attached on the nominal stem and the agreement concords attached on the nominal modifiers; each noun class has affixes unique to its own class. This noun class forms a basis for agreement marking. The agreement markers manifest on the syntactic constituents like the adjectives, numerals, demonstratives, quantifiers, verbs and others. All the concords are governed by the inherent noun class of the head noun, for example the noun class 1 triggers agreement markings of noun class 1 .

Being an agglutinating, noun centric language, Olusuba is morphosyntactically very rich; its syntactic structures are heavily influenced by the morphology of the noun: The 
morphological structure of nearly all words in a structure revolve around the noun. This is manifested in the features which occur across morphology and syntax. These features are identified through inflectional morphology. Kibort (2007) ${ }^{[8]}$ purports that for a feature to be relevant to syntax it must be involved in either syntactic agreement or government. From the Olusuba morphology it is clear that number, and person features are involved in either agreement and are therefore typical morphosyntactical features.

Person as a morphosyntactic feature in Olusuba is typically a feature of agreement, it is an inherent feature found on controllers of agreement. The controllers of agreement in person are linguistic elements that express syntactic arguments - these are typically nouns or pronouns, but may also be pronominal affixes.

Number in Olusuba is a central morphosyntactic feature; it participates in agreement, and is expressed on the controller (the noun or pronoun) as in the majority of languages where number is inflectional, and on all the nominal modifiers and the verb. Number is central in Olusuba's syntax because of the noun class patterning that view singular and plural as distinct features.

This study has shown the significant role that structure of the noun plays in the overall understanding of the syntax of Olusuba. It has clearly shown the significance of syntax in the formation of different word forms.

\section{References}

[1] Austine, P. (ed.) (2003) Language documentation and Description. Vol. 1-6. London: Hans Rausing Endangered Languages Project, School of Oriental and African Studies.
[2] Himmelmann, N. (1998) Documentary and descriptive linguistics. Linguistics, vol.36: 161-195. Cambridge: Cambridge University Press.

[3] UNESCO (2007) Language Vitality and Endangerment http://portal.unesco.org./culture/en/ev.php-URL=9105

[4] Grimes, B. (2000) Ethnologue (fourteenth edition) Dallas Summer Institute of Linguistics.

[5] Halle, M. and Marantz, A. (1993) Distributed Morphology and the Pieces of Inflection: The View from Building 20 Cambridge MA: MIT Press.

[6] Ngonyani, D. (1996) The Morphosyntax of Applicatives: UCLA PhD Dessertation

[7] Ngugi Wa Thiongo, N. (2009) Something Torn and New: An African Renaissance Nairobi: Basic Books Press.

[8] Kibort, A. (2007) Towards a Typology of Grammatical Features Oxford: OUP.

[9] Meinhof, C. (1906) Comparative Grammar studies of the Bantu Languages

[10] Ayot, T. (1987) A History of the Luo of Western Kenya From A. D. 1960-1940: Nairobi: East African Literature Bureau.

[11] Matta, N. (2011) Okusoma Olusuba Kunyoowu no Omanyire Okusoma Olusuanya Nairobi: BTL.

[12] Ogone, J. (2008) Evaluating Language Revitalization in Kenya: the Contradictory Face and Rotland, F. \& Okombo, D. (1986) The Suba of Kenya: A Case of Growing ethnicity with Receding Language Competence. In Afrikanistiche Arbeitspapiere (sept) pp 115Place of the Local Community Factor: Nordic Journal of African studies 17(4)

[13] Census Report (2010) Government of Kenya Census Report 